\title{
Genetic relationships among Turkish sheep
}

\author{
Metehan UZUN ${ }^{\mathrm{a}}$, Beatriz GUTIÉRREZ-GIL ${ }^{\mathrm{b}}$, Juan-José ARRANZ ${ }^{\mathrm{b}}$, \\ Fermín SAN PRIMITIVO $^{\mathrm{b}}$, Mustafa SAATCI ${ }^{\mathrm{c}}$, Mehmet KAYA ${ }^{\mathrm{a}}$, \\ Yolanda BAYÓN ${ }^{\text {b* }}$ \\ a Department of Physiology, Faculty of Veterinary Medicine, Kafkas University, \\ 36040 Kars, Turkey \\ ${ }^{\mathrm{b}}$ Department of Animal Production, University of León, E-24071 León, Spain \\ ${ }^{c}$ Department of Animal Science, Kafkas University, 36040 Kars, Turkey
}

(Received 11 October 2005; accepted 18 April 2006)

\begin{abstract}
Genetic relationships among Turkish sheep breeds were analysed on the basis of 30 microsatellite markers. Phylogenetic analyses based on the estimation of genetic distances revealed the closest relationships for the Akkaraman, Morkaraman and Tuj breeds, which were clearly differentiated from the others in the dendrogram. Our pattern was completely confirmed by results from the Factorial Correspondence Analysis. All the results described analysing either population parameters or individuals revealed a clear separation between the fat-tailed group and the others. These results, based on nuclear DNA, are discussed along with those already reported for these breeds through the investigation of mitochondrial DNA, which had revealed the invaluable significance of the genetic background of these Turkish sheep.
\end{abstract}

DNA microsatellites / local sheep breeds / genetic relationships

\section{INTRODUCTION}

The earliest evidence of sheep domestication was found in certain parts of the Near East, with Turkey as an area of major importance $[2,10]$. Until very recently, this process was supposed to have occurred from only two different subspecies. In this regard, Hiendleder et al. [13] suggested that these subspecies had led to the two distinct mitochondrial types found in sheep breeds, designated as B and A and which are found more frequently in European and Asiatic sheep, respectively. However, a recent study carried out by us on mitochondrial DNA in Turkish sheep [20] revealed the existence of a third maternal lineage (designated as lineage $\mathrm{C}$ ) in that species. This finding suggests that the

*Corresponding author: yolanda.bayon@unileon.es 
sheep domestication process is more complex than previously thought, involving at least three maternal origins and it also reveals that Turkish sheep own a genetic background of enormous relevance.

The international community's awareness of the importance of preserving genetic resources has progressively increased in recent years, with the FAO having made a great effort in this regard. In order to evaluate the genetic importance of each breed, this organisation [8] suggested measuring the genetic variation underlying the differences within and between breeds, recommending the estimation of genetic distances as one of the most suitable methods. To this end, many studies have been performed in sheep among other livestock species (reviewed by [4]). Genetic distances provide information about the phylogenetic relationships between populations and breeds, molecular markers such as microsatellites having proved very useful for this purpose.

The aim of the present study was to contribute to the knowledge of the invaluable genetic background of Turkish sheep breeds through the estimation of their genetic relationships on the basis of the nuclear DNA variation exhibited at microsatellite markers, and to compare the results with the information previously reported for mitochondrial DNA.

\section{MATERIALS AND METHODS}

\subsection{Animals}

A total of 255 animals belonging to five Turkish sheep breeds were analysed. The sample was made up as follows: Akkaraman $(n=56)$, Hemsin $(n=43)$, Karayaka $(n=50)$, Morkaraman $(n=53)$ and Tuj $(n=53)$. Spanish Churra sheep $(n=52)$ were also included in the study as a foreign reference breed. Sampling of unrelated animals conforming to the morphological standard of the breed was carried out in several locations involving 4, 4, 5, 5 and 6 flocks for Akkaraman, Hemsin, Karayaka, Morkaraman and Tuj sheep, respectively, representing 10.6 animals per flock on average.

The area of the main distribution of the Turkish sheep studied is shown in Figure 1. Information about these breeds is available in Mason [18]. The Akkaraman (White Karaman) and Morkaraman (Red Karaman) breeds are fattailed sheep making up the largest indigenous ovine populations in Turkey. The former are located over a wide area of central Anatolia, while the latter are reared throughout eastern Anatolia and also in western Iran. Among other differential characteristics, coat colour is the most distinguishable. Tuj (Tushin) sheep, also fat-tailed animals (originally fat rumped), originate from 


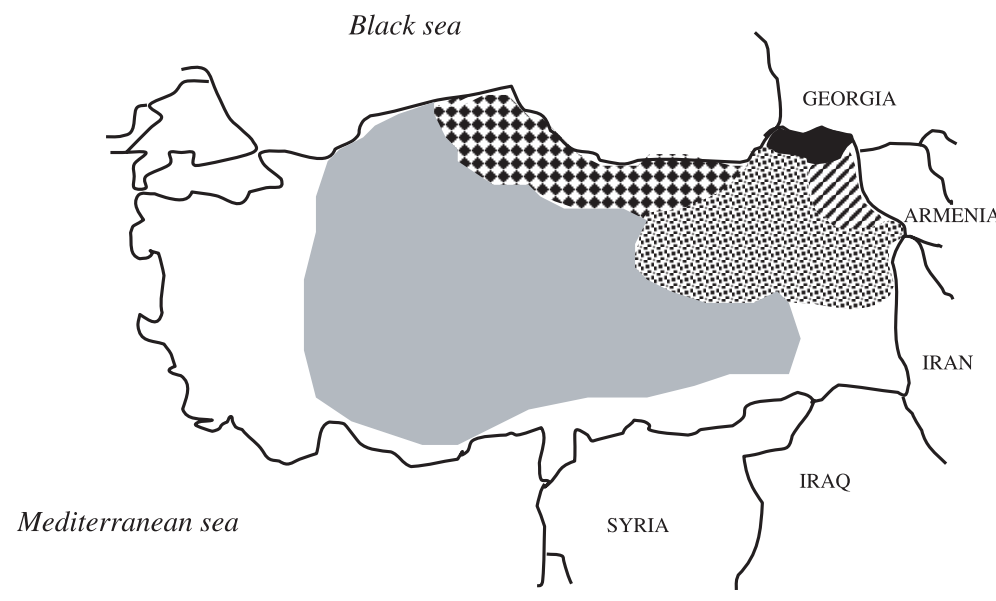

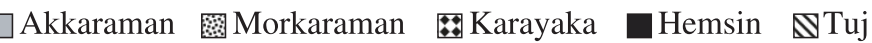

Figure 1. Geographical location of the Turkish sheep studied.

the Caucasus area and are found throughout north-eastern Turkey, where they are well adapted to the physical and climatic conditions of the highlands. Hemsin (Hemşin) sheep constitute a local population found in a restricted area of the eastern Black Sea coast and north-eastern Turkey. They have long tails with fat at the base. Information about this breed is scarce. Karayaka sheep are long-thin-tailed small-sized animals reared throughout the Black Sea area, well adapted to a rainy climate. All these breeds are reared for a combined production (meat, wool and milk), although with differences regarding their main purpose $[1,24,25]$.

\subsection{Methodology}

Blood samples were collected and genomic DNA was isolated using a purification Kit (Promega). Thirty microsatellites from different chromosomal locations were amplified using the multiplex technique that allowed the simultaneous amplification of several markers and the resulting fragments were separated in three electrophoretic runs on an ABIPRISM 377 sequencer. The polymerase chain reaction (PCR) was performed in a total volume of $10 \mu \mathrm{L}$ containing $50 \mathrm{ng}$ of genomic DNA, $1.5 \mathrm{mM}$ of $\mathrm{MgCl}_{2}, 200 \mu \mathrm{M}$ of each dNTP, $0.240 \mu \mathrm{M}$ of each primer, and 0.5 unit of Taq polymerase. Detailed information about the genotyping procedure is shown in Table I. Allelic identification was carried out using the Genescan and Genotyper sequencer software. 
Table I. Microsatellite genotyping procedure.

\begin{tabular}{|c|c|c|c|c|}
\hline Multiloading & Multiplex & $\begin{array}{c}\text { Melting T } \\
\text { Fluorochrome }\end{array}$ & Marker & Allele range \\
\hline \multirow[t]{12}{*}{1} & \multirow[t]{4}{*}{$\mathrm{A}$} & $55^{\circ} \mathrm{C}$ & BMS1948 & $80-100$ \\
\hline & & 6-FAM & FAS & $145-173$ \\
\hline & & & MCMA26 & $191-228$ \\
\hline & & & CSRD2111 & $320-348$ \\
\hline & \multirow[t]{4}{*}{ B } & $65^{\circ} \mathrm{C}$ & OARCP49 & $81-115$ \\
\hline & & TET & CSRD263 & $132-152$ \\
\hline & & & MCM1 & $168-180$ \\
\hline & & & OARKP6 & $190-212$ \\
\hline & \multirow[t]{4}{*}{$\mathrm{C}$} & $55^{\circ} \mathrm{C}$ & BM2504 & $129-157$ \\
\hline & & HEX & CSSM015 & 179-195 \\
\hline & & & CSSM008 & $205-220$ \\
\hline & & & LSCV29 & $236-260$ \\
\hline \multirow[t]{9}{*}{2} & \multirow[t]{2}{*}{$\mathrm{A}$} & $60^{\circ} \mathrm{C}$ & BMS1290 & $124-151$ \\
\hline & & 6-FAM & BM3413 & $178-205$ \\
\hline & \multirow[t]{4}{*}{ B } & $55^{\circ} \mathrm{C}$ & OARCP23 & 86-107 \\
\hline & & TET & BMS522 & $113-126$ \\
\hline & & & RBP3 & $132-159$ \\
\hline & & & CSSM43 & $235-270$ \\
\hline & \multirow[t]{3}{*}{$\mathrm{C}$} & $55^{\circ} \mathrm{C}$ & BMS975 & $77-105$ \\
\hline & & HEX & TGLA53 & $116-145$ \\
\hline & & & HMHR1 & $166-198$ \\
\hline \multirow[t]{9}{*}{3} & \multirow[t]{4}{*}{$\mathrm{A}$} & $55^{\circ} \mathrm{C}$ & BM8125 & $104-124$ \\
\hline & & 6-FAM & CSSM031 & $127-168$ \\
\hline & & & ILSTS005 & $188-210$ \\
\hline & & & SPS115 & $235-253$ \\
\hline & \multirow[t]{2}{*}{ B } & $55^{\circ} \mathrm{C}$ & MCM527 & 164-190 \\
\hline & & TET & ILSTS011 & $272-291$ \\
\hline & \multirow[t]{3}{*}{$\mathrm{C}$} & $58^{\circ} \mathrm{C}$ & MCM53 & $76-101$ \\
\hline & & HEX & RM006 & $108-139$ \\
\hline & & & BM6526 & $145-175$ \\
\hline
\end{tabular}

\subsection{Computations}

Allele frequencies and gene diversity were estimated using GENETIX software (version 4.03) by [5]. Genetic distances and phylogenetic trees were obtained using the POPULATIONS 1.2.29 computer program [14]. The Nei standard genetic distance [19] and Reynolds genetic distance [21] were estimated. 
Table II. Genetic distances between sheep breeds: $D_{S}$ above diagonal and $D_{\text {Reynolds }}$ below diagonal.

\begin{tabular}{ccccccc}
\hline & Akkaraman & Hemsin & Karayaka & Morkaraman & Tuj & Churra \\
\hline Akkaraman & & 0.135 & 0.151 & 0.053 & 0.092 & 0.169 \\
Hemsin & 0.038 & & 0.139 & 0.137 & 0.139 & 0.192 \\
Karayaka & 0.041 & 0.040 & & 0.143 & 0.149 & 0.211 \\
Morkaraman & 0.010 & 0.039 & 0.039 & & 0.078 & 0.167 \\
Tuj & 0.022 & 0.040 & 0.040 & 0.017 & & 0.183 \\
Churra & 0.047 & 0.057 & 0.060 & 0.046 & 0.048 & \\
\hline
\end{tabular}

The Nei standard distance was chosen for comparison purposes since it appears to be the most extensively used in livestock [4]. The Reynolds distance was obtained since it has been suggested as the most suitable for short-term evolution investigations, for which divergence is expected to be mainly due to genetic drift [15]. The neighbour-joining algorithm [23] was used to construct the trees and the bootstrap resampling methodology (1000 replicates) was performed to test the robustness of the dendrogram topology. An unrooted tree was depicted, following the recommendations of Edding and Laval [7]. Also, a Factorial Correspondence Analysis was performed based on the individual multilocus genotype using the GENETIX program. This methodology condenses the information into a few variables and allows a spatial representation of populations or individuals with respect to the defined axis.

\section{RESULTS}

The within breed variability at 30 microsatellites in Turkish sheep was high. The mean number of alleles per locus ranged from 9.3 to 10.4, except for Hemsin sheep ( 7.8 variants on average). Gene diversities varied within a narrow range: from 0.694 in Hemsin to 0.738 in the Tuj population. Spanish Churra sheep, used as a reference breed, exhibited an average of 9.2 alleles per locus and a gene diversity of 0.726 . No consistent $\mathrm{H}-\mathrm{W}$ equilibrium deviations were found, across populations, for any of the loci analysed [11], thus these microsatellites may be considered as adequate for analysing relationships between these breeds.

The values estimated for the Nei standard genetic distance $\left(D_{S}\right)$, and Reynolds genetic distance $\left(D_{\text {Reynolds }}\right)$ are included in Table II, both parameters being in total accordance regarding the relationships established between breeds. As expected, the greatest values were those estimated involving Churra sheep $\left(D_{\text {Reynolds }}=0.046-0.060\right.$ and $\left.D_{S}=0.167-0.211\right)$. Among the 


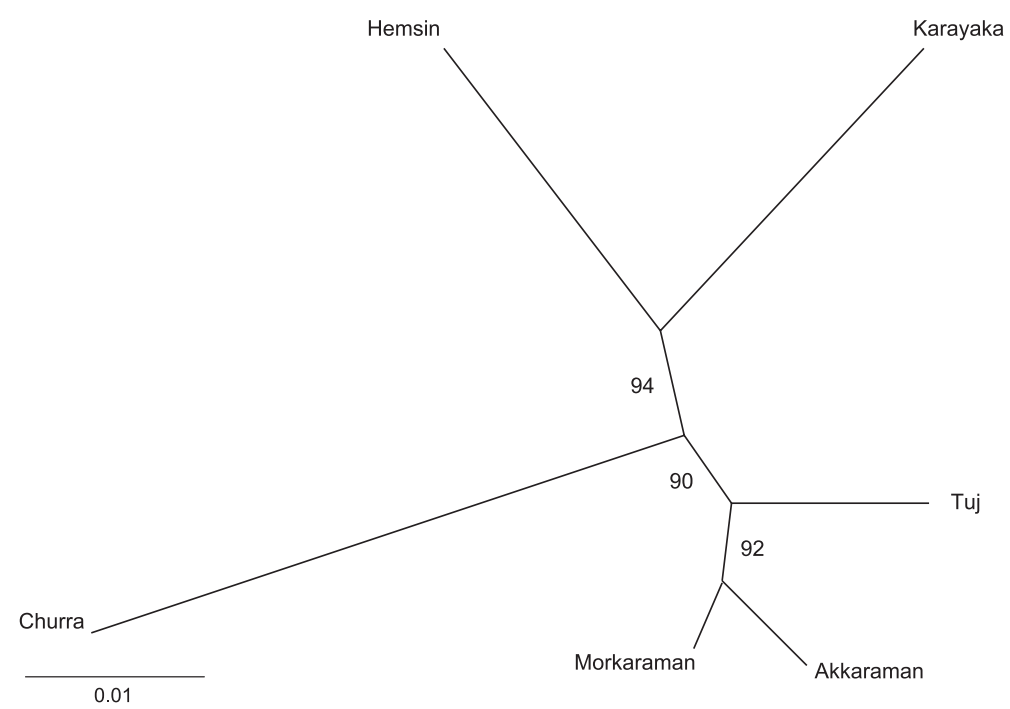

Figure 2. Unrooted neighbour-joining dendrogram showing the genetic relationships among sheep breeds using $D_{\text {Reynolds }}$ genetic distance from 30 microsatellite loci. The numbers indicate the percentage of a group's occurrence in a bootstrap resampling of 1000 trees.

Turkish sheep, markedly low values are to be noticed involving the Akkaraman, Morkaraman and Tuj breeds, both from $D_{\text {Reynolds }}(0.010-0.022)$ and $D_{S}(0.053-0.092)$ distances, when compared with the rest of the analysed pairs. The Morkaraman/Akkaraman pair showed the closest relationship. Karayaka and Hemsin sheep showed high distance values with any breed from the Akkaraman/Morkaraman/Tuj group and also from each other. Figure 2 shows the unrooted neighbour-joining dendrogram obtained from the $D_{\text {Reynolds }}$ genetic distance; the bootstrap values show the topology of the tree to be highly consistent. The same topology was obtained from the $D_{S}$ distance (tree not shown). Churra sheep proved to be the most separated breed. Among the Turkish sheep, the Akkaraman/Morkaraman/Tuj group appear differentiated from the Hemsin and Karayaka breeds.

Spatial representation for the first three axes defined by the Factorial Correspondence Analysis is shown in Figure 3 for the breeds studied. Axis 1 explains $27.63 \%$ of the inertia and it clearly distinguishes the Churra breed from Turkish sheep. The marker alleles with the greatest contribution to this differentiation were as follows: "151" at locus BMS1290, "180" at locus HMH1R and "130" at locus TGLA53. The figure also shows a close relationship of the Akkaraman/Morkaraman/Tuj group and the separation of Hemsin and 


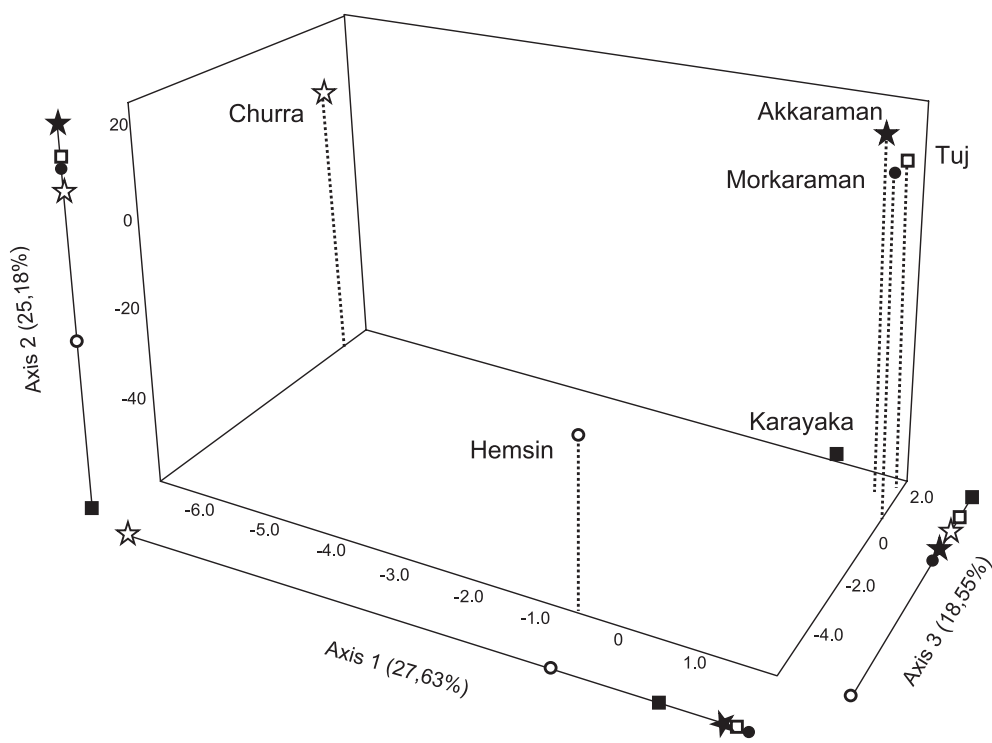

Figure 3. Spatial representation of the breeds as defined by the Factorial Correspondence Analysis: percentage of inertia explained by each axis in parentheses.

Karayaka breeds from any other breed. Axis 2 separated, in a greater extent, Karayaka sheep, mainly based on the following marker alleles: "82" at locus BMS975, "252" and "270" at locus CSSM43 and "89" at locus OARCP49. For its part, axis 3 differentiates the Hemsin population from the other sheep breeds, involving as major contributing alleles, variant "92" at locus BMS975 and variant "144" at locus CSRD263.

Figure 4 shows the spatial representation of all individuals from the Factorial Correspondence Analysis, revealing the highest degree of dispersion among individuals belonging to the same breed to occur among Churras. Furthermore, very little overlapping is evident among individuals belonging to the breeds differentiated in Figure 4: Churra, Hemsin and Karayaka. A comparison of these two Turkish breeds shows a higher degree of dispersion among Karayaka than Hemsin sheep. Finally, individuals from the Akkaraman, Morkaraman and Tuj groups appear to be closely interrelated, indicating a high genetic proximity among individuals from the three populations.

\section{DISCUSSION}

All the results described reveal a clear separation between the fat-tailed group and the other breed types, and a possible effect of inbreeding on this 


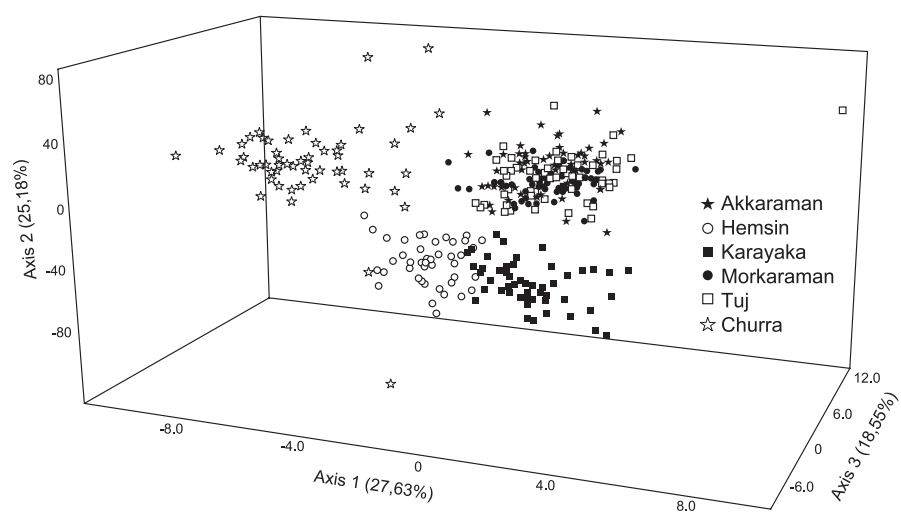

Figure 4. Spatial representation of the individuals as defined by the Factorial Correspondence Analysis: percentage of inertia explained by each axis in parentheses.

differentiation may be discarded since several parameters estimated in these populations indicate that their inbreeding rate is not high [11]. Genetic distances pointed to the Akkaraman/Morkaraman pair as the closest one. These are both fat-tailed sheep reared along wide areas with the most numerous populations, together representing $70 \%$ of the sheep in Turkey. They show, however, important differential characteristics. The indigenous Turkish Akkaraman breed, which numerically represents nearly half of all sheep farmed in this country, are white animals reared mainly for meat. For their part, the reddishbrown Morkaraman sheep of greater rusticity are well adapted to tough environmental conditions and are mainly reared for their coarse wool. Tuj sheep, which appear tightly grouped with the Akkaraman/Morkaraman pair, are also fat tailed animals although with some peculiarities in the pattern of fat accumulation, since they are either short-fat-tailed or fat-rumped sheep. Tuj sheep are white animals with coarse wool, considered to originate from the Georgian Tushinsky sheep, and they can be found in north-eastern Turkey. The original Caucasian sheep is known to accumulate fat in the rump but they do not have a fat tail. The pattern of fat accumulation in Tuj sheep currently kept in Turkey is probably the result of crossings with local fat-tailed breeds as explained by Yarkin and Eker [25]. This breed is also called the Turkish Tuj to differentiate it from the original Caucasian form. This might explain the close relationship exhibited in our study with Akkaraman and Morkaraman breeds.

Karayaka and Hemsin sheep, which appear clearly separate from the Morkaraman/Morkaraman/Tuj group, and also from each other, show a quite different pattern of fat distribution from those already described. Karayaka sheep are long-thin-tailed animals with no fat in the tail, while Hemsin also 
has a long tail with a small amount of fat accumulated just at the tail base. Karayaka are indigenous to Turkey and found in the vicinity of the Black Sea throughout northern Anatolia, where they are well adapted to the rainy climate. The Hemsin breed is represented by a small population reared in a very restricted area of north-eastern Turkey, close to the Black sea, on the borders with other countries, and little information is available about the breed. These sheep show no colour uniformity, being white, brown or black.

The results of nuclear microsatellite analysis indicate that the current degree of genetic relationships between Turkish sheep breeds was largely in accordance with classifications based on the tail fat distribution. However, no contribution from other morphological traits such as wool type or colour was evident. The results from the analysis of genetic markers are not always in total accordance with morphological classifications (e.g. Arranz et al. [3]). In this regard, microsatellites, which are considered as selectively neutral markers, are expected to reflect the evolutionary relationships of populations more accurately [8].

It is generally accepted that, unlike production characteristics, main changes in morphological traits (easily observable and determined by relatively few genes) occurred in very early civilisations [17]. Particularly, the lengthening of the tail is considered as one of the major changes that followed domestication. Also, from available artistic representations, it is known that distinct patterns of fat accumulation in the tail of sheep have existed since antiquity in the Middle East, where, according to Ryder [22], sheep have been depicted with both types of tail. This author indicates that the earliest fat-tailed animals represented had a short, broad tail and that breeding was probably directed towards an increase of fat-carrying capacity, since sheep depicted later, during Babylonian and Assyrian times, had a long fat tail.

The data from the present study indicate that the separation between the fat tailed and non-fat tailed sheep investigated, reflect differences at a genome level. When we compare these results with those obtained through the investigation of mitochondrial DNA of the same breeds [20] the information obtained is quite different and complementary. The most important conclusion derived from the mtDNA analysis was the identification of three different maternal lineages, instead of the two mtDNA types (B and A) reported in sheep by Hiendleder et al. [13]. Interestingly, all mtDNA types (including the rare type C) were identified in all breeds analysed (Akkaraman, Morkaraman, Tuj, Hemsin and Karayaka) and in some of them type $\mathrm{C}$ was very frequent.

The joint analysis of nuclear and mtDNA data yields helpful information on the origin and genetic relationships of modern breeds. For example, the 
Akkaraman and Morkaraman breeds (which proved very close on a nuclear genomic base) greatly differed in the frequency of mtDNA types. Akkaraman sheep, an indigenous Turkish breed, showed a high frequency of mtDNA type $\mathrm{C}$, whereas the Morkaraman breed had a clear predominance of lineage A (also known as the Asiatic type) [12], in accordance with the location of this breed in eastern Turkey and western Iran. So these two breeds seem to differ in their maternal origin, the close relationship detected from nuclear data originating via the male line.

For their part, Tuj and Hemsin sheep, which differ a lot on a nuclear basis, do not show such differences on mtDNA examination. Yet type B (or the European type) [12] proves to be clearly predominant in both breeds, in great contrast with the others. Their maternal origin might therefore be very similar, which would be in accordance with their present location in northern Turkey. This information throws a good deal of light on Hemsin sheep, which are thought to have remained isolated from other breeds, but about which very little is known. The information available about Tuj sheep indicates their origin from a Caucasian breed and subsequent crossbreeding with fat-tailed Turkish sheep and other Caucasian breeds, whereby morphological changes arose, particularly regarding the tail fat accumulation already described, as reported by Yarkin and Eker [25]. This crossbreeding process would have also determined the current close genetic relationship revealed in the present study from nuclear DNA analysis. Finally, Karayaka sheep, for which the present study revealed a considerable genetic differentiation from other breeds from nuclear microsatellite markers, showed a pattern of distribution of mtDNA types which also differed from the remaining breeds, although with a remarkable similarity with Akkaraman sheep, as in the very high presence of the rare mtDNA type $C$. This suggests a similar maternal origin for these two sheep indigenous of Turkey and a later differentiation by male crossing.

As Bruford [6] states, we have to take into consideration that mitochondrial DNA (almost exclusively maternally inherited) is more accurate when investigating the domestication processes, but it does not detect male-mediated flow and then is less sensitive to introgression or gene flow processes, which are more probably produced via males. On the contrary, as shown in the present study, nuclear data are more powerful for analysing more recent evolutionary processes, brought about to a greater extent through a male line, and they are also more suitable as a representation of overall genomic diversity. The results obtained here for the genetic relationships among Turkish sheep are highly relevant since little information is available about their origin, while in some cases, such as Hemsin sheep, very little is known about the breed at all. 
As in previous work on other livestock species such as cattle (e.g. MacHugh et al. [16]) or pigs (e.g. Giuffra et al. [9]), the information obtained in our study from nuclear DNA proves complementary to data from a mitochondrial origin. Together, all this information contributes to the analysis of the evolutionary process giving rise to the relationships of modern sheep breeds.

\section{ACKNOWLEDGEMENTS}

This work was supported by the Castilla and León regional government (Convenio de Colaboración con la Consejería de Agricultura y Ganadería) and by the State Planning Organisation (DPT) of Turkey.

\section{REFERENCES}

[1] Akcapinar H., Koyun Yetistiriciligi, 2nd edn., Ismat Matbacilik, Ankara, 2000.

[2] Akcapinar H., Ozbeyaz C., Hayvan yetistiriciligi temel bilgileri, 1st edn., Kariyer Matbaacilik, Ankara, 1999.

[3] Arranz J.J., Bayón Y., San Primitivo F., Differentiation among Spanish sheep breeds using microsatellites, Genet. Sel. Evol. 33 (2001) 529-542.

[4] Baumung R., Simianer H., Hoffman I., Genetic diversity studies in farm animals - a survey, J. Anim. Breed. Genet. 121 (2004) 361-373.

[5] Belkhir K., Borsa P., Goudet J., Chikhi L., Bonhomme F., GENETIX, logiciel sous WindowsTM pour la génétique des populations. Laboratoire Génome, Populations, Interactions CNRS UMR 5000, Université de Montpellier II, Montpellier, 1996.

[6] Bruford M.W., Bradley D.G., Luikart G., DNA markers reveal the complexity of livestock domestication, Nat. Rev. Genet. 4 (2003) 900-910.

[7] Edding J.H., Laval G., Measuring genetic uniqueness in livestock, in: J.K. Oldenbroeck (Ed.), Genebanks and the Conservation of Farm Animal Genetic Resources, DLO Inst. Anim. Sci. and Health, Lelystad, 1999, pp. 33-58.

[8] FAO Food and Agriculture Organisation of the United Nations, Secondary Guidelines for Development of National Farm Animal Genetic Resources Management Plans. Measurement of Domestic Animal Diversity (MoDAD): Original Working Group Report, http://dad.fao.org./en/refer/ library/guidelin/ workgrp.pdf, 1998.

[9] Giuffra E., Kijas J.M.H., Amarger V., Carlborg Ö., Jeon J.-T., Andersson L., The origin of the domestic pig: independent domestication and subsequent introgression, Genetics 154 (2000) 1785-1791.

[10] Gupta A.K., Origin of agriculture and domestication of plants and animals linked to early Holocene climate amelioration, Curr. Sci. 87 (2004) 54-59.

[11] Gutiérrez-Gil B., Uzun M., Arranz J.J., San Primitivo F., Yildiz S., Cenesiz M., Bayón Y., Genetic diversity in Turkish sheep, Acta Agr. Scand. Am (In press) DOI: 10.1080/09064700600641681. 
[12] Hiendleder S., Mainz K., Plante Y., Lewalski H., Analysis of mitochondrial DNA indicates that domestic sheep are derived from two different ancestral maternal sources. No evidence for contributions from urial and argali sheep, J. Hered. 89 (1998) 113-120.

[13] Hiendleder S., Kaupe B., Wassmuth R., Janke A., Molecular analysis of wild and domestic sheep questions current nomenclature and provides evidence for domestication from two different subspecies, P. Roy. Soc. Lond. B 269 (2002) 893-904.

[14] Langella O., POPULATIONS 1.2.29. Population genetic software (individuals or populations distances, phylogenetic trees), http://www.cnrs-gif.fr/pge, 2004.

[15] Laval G., SanCristobal M., Chevalet C., Measuring genetic distances between breeds: use of some distances in various short term evolution models, Genet. Sel. Evol. 34 (2002) 481-507.

[16] MacHugh D.E., Shriver M.D., Loftus R.T., Cunningham P., Bradley D.G., Microsatellite DNA variation and the evolution, domestication and phylogeography of taurine and zebu cattle (Bos taurus and Bos indicus), Genetics 146 (1997) 1071-1086.

[17] Maijala K., Genetic aspects of domestication, common breeds and origin, in: L. Piper, A. Ruvinsky (Eds.), The Genetics of Sheep, CAB International, Wallingford, 1997, pp. 13-49.

[18] Mason I.L., A world dictionary of livestock breeds, types and varieties, 4th edn., C.A.B. International, 1996.

[19] Nei M., Genetic distance between populations, Am. Nat. 106 (1972) 283-292.

[20] Pedrosa S., Uzun M., Arranz J.J., Gutiérrez-Gil B., San Primitivo F., Bayón Y., Evidence of three maternal lineages in Near Eastern sheep supporting multiple domestication events, P. Roy. Soc. Lond. B 272 (2005) 2211-2217.

[21] Reynolds J., Weir B.S., Cokerham C.C., Estimation of the coancestry coefficient: basis for a short-term genetic distance, Genetics 105 (1983) 767-779.

[22] Ryder M.L., Sheep, in: I.L. Mason (Ed.), Evolution of Domesticated Animal, Longman, London, 1984, pp. 63-85.

[23] Saitou N., Nei M., The neighbor-joining method: a new method for reconstructing phylogenetic trees, Mol. Biol. Evol. 4 (1987) 406-425.

[24] Soysal M.I., Özkan E., Gürcan E.K., The status of native farm animal genetic diversity in Turkiye and in the world, Trakia J. Sci. 3 (2003) 1-12.

[25] Yarkin I., Eker M., Kars cevresinde yetisitirlen Tuj koyunu uzerinde calismalar, A.U. Ziraat Fak. Yilligi. 26 (1954) 376-388. 